\title{
Cost Analysis of Haemodialysis Patients in Government Tertiary Care Centre - A Pharmacoeconomic Study
}

\author{
Manjula $\mathrm{MJ}^{1}$, Deepak $\mathrm{P}^{1}$, Suresh $\mathrm{RM}^{2}$, Raghu $\mathrm{N}^{1}$ \\ ${ }^{1}$ Department Of Pharmacology, Hassan Institute of Medical Sciences, \\ Hassan, Karnataka - India \\ ${ }^{2}$ Department Of General Medicine, Hassan Institute of Medical Sciences, \\ Hassan, Karnataka - India
}

\begin{abstract}
The progression of chronic kidney disease (CKD) to End-Stage Renal Disease (ESRD) in India is rapidly increasing. Over 25 million of the people suffering from ESRD, especially from rural area. Many of these patients are not undergoing dialysis due to the factors such as lack of awareness, fewer treatment options, unaffordability prices due to low income, and minor reimbursement for chronic illness. The cost of hemodialysis in private hospitals is around 12.000 INR (Indian Rupee) per person monthly and 140.000 INR per year, which seem too expensive for middle and lower-middle class of patients. Hence our study was aimed to analyse the healthcare cost of haemodialysis in government tertiary health care centres by analysing the direct and indirect cost from the patient perspective. Sixty patients who underwent dialysis in Hassan Institute of Medical Sciences Teaching Hospital were included in this study. The demographic details, past and present medical history, cost per session of dialysis, laboratory examination, money spent on travel, and the working days lost were calculated. Out of 60 patient (male: 47; female: 17), 53 patients aged 18-65 years old. They belonged to lower-middle (38.33\%), middle (23.33\%), lower $(21.66 \%)$, and uppermiddle class $(8 \%)$. The average direct medical cost of each patient in one session of dialysis was 481.5 INR and indirect medical costs were 557.33 INR. Based on our observation, we conclude that the patients are having satisfactory outcomes, comparatively at low cost in our government dialysis unit. Government should encourage and also cover the mobile dialysis centres under government health schemes, by which the indirect medical cost can be reduced.
\end{abstract}

Keywords: Pharmacoeconomic, Cost Analysis, Dialysis Unit, Government Tertiary Health Care Centre

Corresponding author: Manjula MJ. Department Of Pharmacology, Hassan Institute of Medical Sciences, Hassan, KarnatakaIndia.Email: manjula.mj03@gmail.com

Received: 4 February 2021. Revised: 5 April 2021 . Published: 30 August 2021 


\section{Introduction}

International Society for Pharmacoeconomics and Outcome Research (ISPOR) defined the pharmacoeconomics as the field of study that evaluates the behaviour of individuals, firms, and markets relevant to the use of pharmaceutical products, services, and programs and which frequently focuses on the costs and consequences of that use. ${ }^{1,2}$ Pharmacoeconomic evaluations have become an important tool in therapeutic decision making especially in chronic illness where there is limited resources. ${ }^{3,4}$

The progression CKD to ESRD in India is rapidly growing due to lack of medical facilities, poor control of risk factors, and delayed referral to nephrologists. ${ }^{5}$ The prevalence of CKD and ESRD are estimated as 7852 and 1870 per million, respectively. The majority of the patients about $60 \%$ will discontinue the therapy within 3 months. ${ }^{6,7}$ More than $75 \%$ of patients suffer from ESRD and do not receive any treatment, especially from rural areas. This is caused by several factors, including lack of awareness, fewer treatment options, unaffordable prices due to low income, minor reimbursement for chronic illness, and unavailability of insurance. ${ }^{8}$ Most of the dialysis units are in the private sector and the average hemodialysis cost in India range between 1200 and 2000 INR per session. The cost of haemodialysis in private hospitals is around 12000 INR per month and 140000 INR per year. ${ }^{9}$

In India, the number of death due to ESRD was 3.78 million in 1990 (40.4\% of all death) and is expected to increase up to 7.73 million in 2020 (66.7\% of all death). Due to delayed diagnosis and failure to take suitable measures to prevent the progression of renal failure, it may result in end stage renal disease at young stage itself. ${ }^{10,11}$
Present study was conducted to analyze the cost associated with haemodialysis in a government tertiary care center in the hospital in patient perspective.

\section{Methods}

This prospective, observational, cross sectional study was conducted in Hassan Institute of Medice Sciences Teaching Hospital. This study was conducted from May to June 2020 for a period 45 days (from May, $15^{\text {th }}$ to June, $30^{\text {th }}$ ).

This study was enrolled after obtaining the intitutional ethics approval Institutional (Ethics Committee, HIMS, HASSAN, Karnataka. Clearance number: IEC/HIMS/ RR117/22-05-2020).

Total of 60 patients were included of this study. There were patients of either sex, diagnosed with ESRD that requiring dialysis, and willing to give a consent. Demographic data of the patient and care taker, and the cost details per dialysis were collected. The cost of dialysis from patient perspective was noted. We analyzed the direct and indirect costs including cost of dialysis, investigations, drugs, food, transportation, lost wages, and etc. Socioeconomic status of the patient was also studied by using modified BG Prasad's classification based on per capita income.

\section{Statistical Analysis}

Data was analysed using descriptive analysis by calculating mean, average and standard deviation.

\section{Results and Discussion}

From a total of 60 patients, 53 patients $(88.33 \%)$ aged between $18-65$ years and 7 patients $(11.66 \%)$ of them were $>65$ years. Average age distribution was $50.65 \pm 8.35$ years (Figure 1). Another study also showed that the average group of patients suffering 


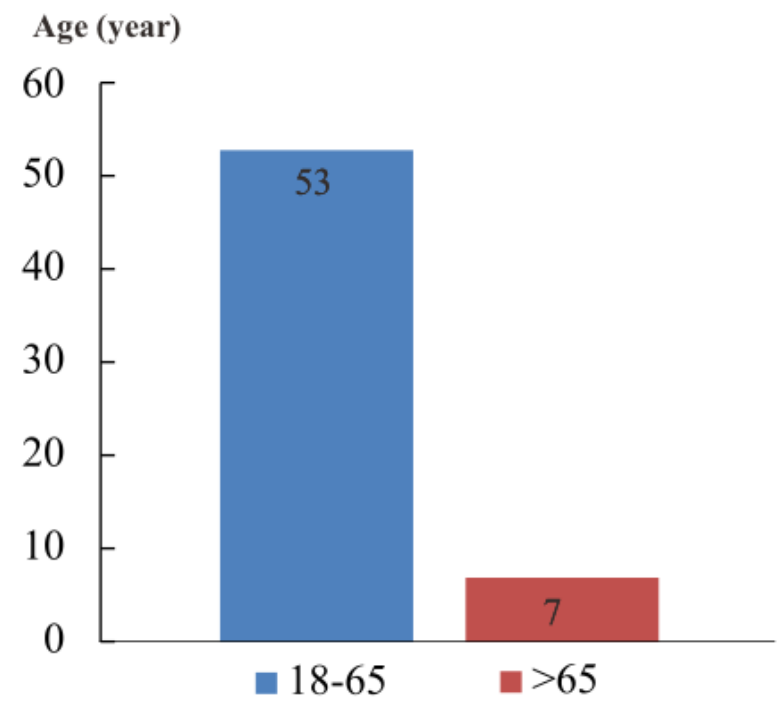

Figure 1: Age Distribution among the Participants

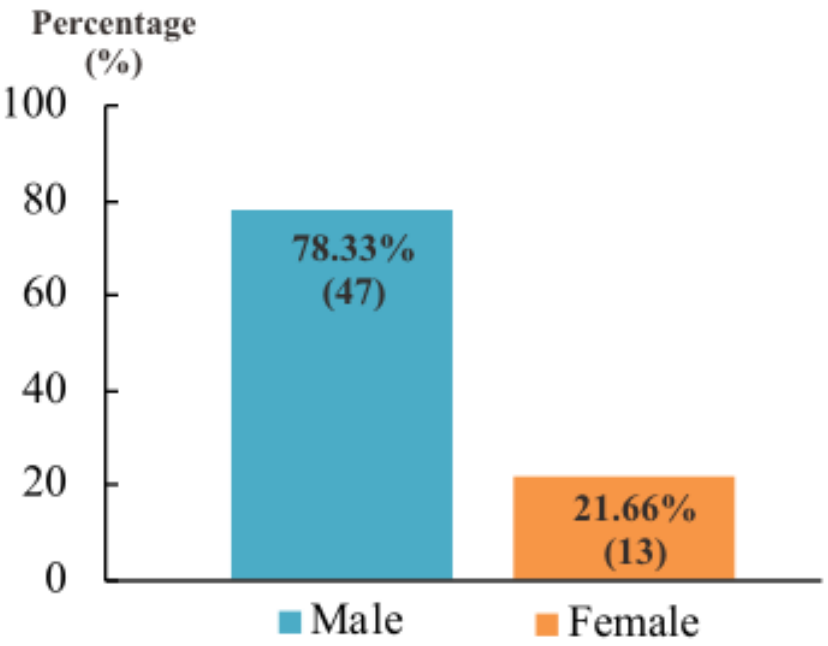

Figure 2. Gender Distribution

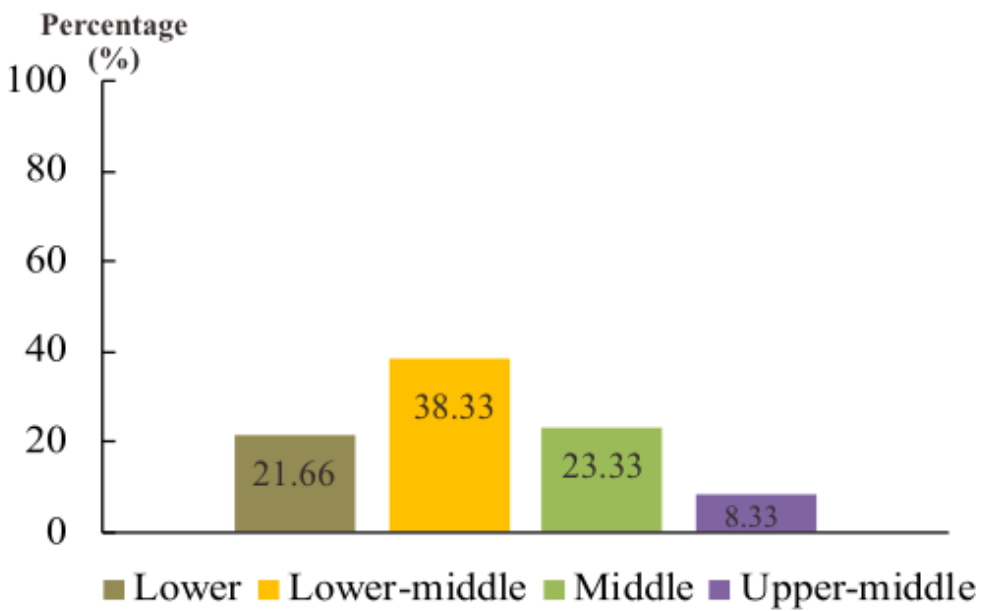

Figure 3. Distribution of Socioeconomic Status 
ESRD were close to our findings (by suja et al:49.72 \pm 13.2 years $^{12}$; by Fathima et al: $51 \pm 12.7$ years ${ }^{13}$ ). Moreover, out of 60 patients, there were 47 males $(78.33 \%)$ and 13 females (21.66\%) (Figure 2). The ratio of male patients were high compared to females. We found the similar observation in the study conducted by Suja et al and Fathima et al in which the study was conducted in a private dialysis unit (male: $66.2 \%$; female: $33.8 \%$ ). ${ }^{13}$

The socioeconomic status of the 60 participants were analysed by using the Modified BG Prasad's classification ${ }^{14}$ based on per capita income. According to the classification, people with $>7008$ INR belongs to upper class, 3504-7007 INR is upper-middle class, 2102-3503 INR is middle-class, 1051-2101 INR is lower-middle class, and $<1050$ INR falls under lower class.

None of the patients participated in our study belongs to upper class. Most of them $(38.33 \%)$ belongs to lower-middle to middle class $(23.33 \%)$ followed by lower class $(21.66 \%)$, whereas, only $8.33 \%$ belongs to upper-middle class (Figure 3). Previous study conducted at private dialysis units showed 18 out of 30 patients were under upper class and 12 patients were in the middle class. There wasn't lower class patients that might due to in unaffordability prices at private units. ${ }^{12}$ On the other hand, most of the patients in the study conducted by Anita et al showed that $40 \%$ patients belonged to lower-middle socioeconomic class. ${ }^{15}$

Comorbid condition most commonly occured among the patients $>50$ years that increase the direct medical cost among this particular age group. People were mostly suffer from hypertension with diabetes, or either hypertension, diabetes, or cardio vascular disease. Minor cases of comorbid conditions were renal artery stenosis, chronic pyelonephrits, and etc. (Table 1). In contrast, major portion of the patients participated in the study by suja et al suffered from hypertension (13 of 30) followed by diabetes (10 of 30) and hypertension with diabetes (5 of 30). Only 2 of them had other conditions. Another study conducted by Anita et al also found that hypertension was the most common comorbidity.

About $95 \%$ of patients were advised for dialysis twice a week and 5\% of them undergoing daily dialysis. (Table 2). Majority of the participated patients in the research work of Fathima et al were also undergoing twice a week dialysis. Which accounted for $89.7 \%$ and $10.3 \%$ were undergoing thrice a week dialysis. All of patients coming for dialysis in our study were satisfied with the treatment and never missed the follow up. According to the report of Kher et al ${ }^{16}, 60 \%$ of the haemodialysis patients were lost to follow up within 3 months because of high cost.

Average cost per session in person was 1028.3 INR, which comes around 12,339.6 INR per month. According to the report by Suja A et al., average cost per dialysis was 4,500 INR and 56\% among that was direct medical cost. Indirect and non-medical cost was $20 \%$ and $24 \%$ respectively. Another study conducted by Fathima et at., had been estimated the average median direct medical cost of 85,999 INR and 14,437 INR was nonmedical cost. These results are comparatively higher compared to our study. (Table 3)

Average direct medical cost per session in person was 481.5 INR (5778 INR monthly). This was had been accounted under the government. But, the direct non medical and indirect cost which accounted for 4188 and 2,499.96 INR respectively had to be paid from their personal funds (Table 4). 
Table 1. Distribution of Comorbid Conditions

\begin{tabular}{ll}
\hline Comorbid Conditions & n (\%) \\
\hline Hypertension & $19(31.66 \%)$ \\
Diabetes & $7(11.66 \%)$ \\
Hypertension with Diabetes & $23(38.33 \%)$ \\
Cardio Vascular Disease & $7(11.66 \%)$ \\
Others & $4(6.66 \%)$ \\
\hline
\end{tabular}

Table 2. Distribution of Frequency of Dialysis

\begin{tabular}{ll}
\hline Frequency of Dialysis & $\mathrm{n}(\%)$ \\
\hline Twice a week & $57(95 \%)$ \\
Daily & $3(5 \%)$ \\
\hline
\end{tabular}

Table 3. Average Cost Per-Session of Dialysis in Person

\begin{tabular}{lc}
\hline $\begin{array}{l}\text { Cost Analysis of Patients } \\
\text { Per-session in Person }\end{array}$ & $\begin{array}{c}\text { Price Amount } \\
\text { (INR) }\end{array}$ \\
\hline Dialysis Charge & 230.00 \\
Investigations & 129.00 \\
Other Drugs & 122.50 \\
Travel & 138.50 \\
Food & 22.00 \\
Loss by Leave & 208.33 \\
Expenses of the Patient Care Taker & 188.50 \\
Total & $1,028.83$ \\
\hline
\end{tabular}

Table 4. Average Direct and Indirect Medical Cost

\begin{tabular}{ll}
\hline Direct Medical cost in INR & 481.5 \\
Direct non-medical cost in INR & Nil \\
Indirect Cost in INR & 557.33 \\
\hline
\end{tabular}

As most of the patients in this study belonged to lower class, this calculated amount is even burden for them and their family. Haemodialysis cost in the article by Anita et $\mathrm{al}^{15}$ ranged between $1200 \mathrm{INR}$ and 2000 INR per session. Most of their patient's undergone weekly thrice session of dialysis. It was cost INR 3,600 per week and INR14,400 per month. Median direct medical costs in Fatima et al was 85,999.2 INR which found to be higher than direct nonmedical costs of
14,437.1 INR. Median cost for each session among the patients was 980 INR (Range 1100-900 INR). ${ }^{13}$

A review by Umesh khanna ${ }^{17}$ stated that, the cost of each haemodialysis session in India varies from 150 INR in government hospitals, to 2000 INR in some corporate hospitals. The cost of an arterio venous fistula construction is 6000 to 20000 INR from a government hospital to varying grades of private 


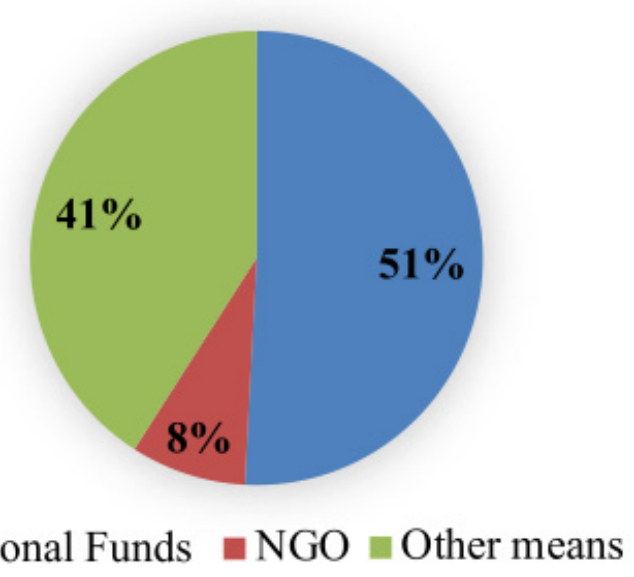

Figure 4. Means of Financial Help

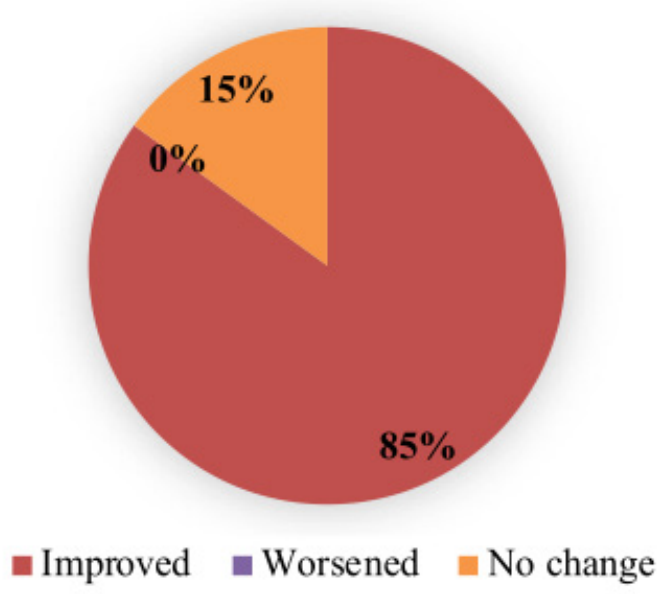

Figure 5. Outcomes of Dialysis

hospitals. The average cost of erythropoietin per month was 4000 to 10000 INR. As most of the patients were belonged to lower and middle class, most of them could afford the cost with the help of relatives, friends, and take a loan. About $8 \%$ of them had a help by non governmental organization (NGO), while others paid used personal funds from their income and savings. (Figure 4)

Regarding the facilities, all patients that underwent the regular dialysis schedule were satisfied with the service provided at the hospital. Several pharmacoeconomic studies have been carried to analyse the direct and indirect medical cost among dialysis patients. But all these have been conducted in private dialysis units. In our study, we included the participants from government tertiary health care centre. The facilities such as admission charges, food, amd nursing charges are free, and dialysis charge has been set minimum. The patient with comorbid conditions have been purchasing few drugs from outside pharmacy, as few required drugs are not available at government health care centre. ${ }^{18}$

Present study which was conducted at government hospital, direct medical cost has been less but indirect medical cost was almost similar to the above mentioned studies. Major portion of the patient in our study belongs to the lower and lower middle class. Few of them belongs to the below 
poverty line (BPL), for whom the dialysis, cost of lab investigations will be half of the non-BPL patients. Economic burden on both BPL and Non-BPL patients will be increased by indirect medical cost itself. Thus, the government must implement the mobile dialysis centres or the number of dialysis centres at $\mathrm{CHCs}$ must me increased in order to reduce the burden on these patients. ${ }^{19,20}$

\section{Conclusion}

Based on our observation, we concluded that the patients were having satisfactory outcomes, comparatively at low cost in our government dialysis unit. Government should encourage and also cover the mobile dialysis centers under government health schemes, by which the indirect medical cost can be reduced.

\section{Acknowledgment}

Department of General Medicine, HIMS, Hassan.

\section{Conflict of Interest}

Nil

\section{Funding}

Nil

\section{References}

1. Pashos CL, Klein EG, Wanke LA. ISPOR Lexicon. 1st ed. Princeton, $\mathrm{N}$. International Society for Pharmacoeconomics and Outcome Research. 1998.

2. Ahmad, A., Patel, I., Parimilakrishnan, S., Mohanta, G. P., Chung, H., \& Chang, J. (2013). The role of pharmacoeconomics in current Indian healthcare system. Journal of research in pharmacy practice.2013.2(1):3-9.

3. Bhowmik, Debjit, S. Duraivel, A. N. Rajalakshmi, and S. Kumar. Pharmacoeconomics-A Review.
Pharmacy.2014.6(9): 672-675

4. Juan GP, Luke V, Sally CS, Sarah W. Haemodialysis for ESRD: A costeffectiveness analysis of treatment options. International Journal of technology assessment in Healthcare 2005;21:32-9.

5. Rajapurkar M, Dabhi M. Burden of disease-prevalence and incidence of renal disease in India. Clinical Nephrology. 2010 Nov 1;74(1):S9.

6. Ballal HS. The burden of chronic kidney disease in a developing country, India. Ouest. 2007;9:12-9.

7. Agarwal SK, Dash SC, Irshad M, Raju S, Singh R, Pandey RM. Prevalence of chronic renal failure in adults in Delhi, India. Nephrology Dialysis Transplantation. 2005; 20:1638-42.

8. Mani MK. Prevention of chronic renal failure at the community level. Kidney International. 2003;(83):S86-9.

9. Crealey GE, Sturgess IK, McElnay JC, Hughes CM. Pharmaceutical care programmes for the Elderly: Economic issues. Pharmaeconomics. 2003;21:455-65.

10. Khanna U. The economics of dialysis in India. Indian journal of Nephrology. 2009; 19:1-4.

11. Dirks J, Zeeuw D, Agarwal S, Atkins R, Rotter R, Amico G, et al. Prevention of the chronic kidney and vascular disease: Towards global health equity-the Bellagio 2004 Declaration. Kidney International. 2005;98:s1-s6.

12. Suja A, Anju R, Anju V, Neethu J, Peeyush P, Saraswathy R. Economic evaluation of end stage renal disease patients undergoing haemodialysis. Journal of Pharmacy and Bioapllied Sciences. 2012 Apr;4(2):107.

13. Fathima S, Mateti UV, Philip ML, Kamath J. Pharmacoeconomic 
evaluation of haemodialysis patients: A study of cost of illness. Journal of Integrative Nephrology and Andrology. 2018 Apr 1;5(2):54.

14. Sharma, Rahul. Revision of Prasad's social classification and provision of an online tool for real-time updating. South Asian Journal of Cancer. 2013;2(3):157.

15. Anita N, Fathima TT, Mrudula G. Pharmacoeconomic evaluation in end stage renal disease patients. Journal of Pharmaceutical Research. 2016 Jan-Mar;16(1):14-18

16. Kher V. End stage renal disease in developing countries. Kidney International. 2002; 62:350-62.

17. Khanna U. The economics of dialysis in India. Indian Journal of Nephrology 2009;19:1-4.

18. Phuong JM, Penm J, Chaar B, Oldfield LD, Moles R. The impacts of medication shortages on patient outcomes: A scoping review. PLoS One. 2019;14(5):e0215837. P

19. Sandeep kudtarkar. Dialysis healthcare delivery in India. Conference paper: Sies Health Care Conference. 2014

20. Setting up of hemodialysis unit. Indian Journal of Nephrology. 2020. 4(30):1-5 